\title{
DO MOTONEURONS SLOW WITH AGING? A SYSTEMATIC REVIEW AND META-ANALYSIS WITH META-REGRESSION
}

Lucas B. R. Orssatto ${ }^{1 *}$, David Borg ${ }^{2}$, Linda Pendrith ${ }^{1}$, Anthony J. Shield ${ }^{1}$, Anthony J. Blazevich $^{3}$, Gabriel S. Trajano ${ }^{1}$

${ }^{1}$ School of Exercise and Nutrition Sciences, Faculty of Health, Queensland University of Technology (QUT), Brisbane, Australia.

${ }^{2}$ Griffith University, Menzies Health Institute Queensland, The Hopkins Centre, Brisbane, Australia.

${ }^{3}$ Centre for Exercise and Sports Science Research (CESSR), School of Medical and Health Sciences, Edith Cowan University, Joondalup, Australia.

*Corresponding author: Lucas B. R. Orssatto (1.betdarosaorssatto@qut.edu.au). 


\section{ABSTRACT}

Nervous system maladaptation is linked to the loss of muscle force production and motor control with aging. However, the mechanisms specifically underpinning these muscle functional limitations remain unclear. Motoneuron discharge rates are a critical determinant of force production and strongly impact motor control; thus, lower discharge rates could underpin force and physical function losses during aging. The present meta-analysis with metaregression summarises the findings of studies comparing motoneuron discharge rates between young and older adults and examines whether a muscle's functional role and anatomical location influences discharge rates across contraction intensities during aging. Meta-analysis revealed lower discharge rates in older compared to young adults in lower body flexor (standardised mean difference, $\mathrm{SMD}=-0.86 ; 95 \% \mathrm{CI}:-1.20,-0.51 ; p<0.001$ ) but not extensor $(\mathrm{SMD}=-0.18 ; 95 \% \mathrm{CI}:-0.50,0.15 ; p=0.29)$ muscles or upper body muscles $(\mathrm{SMD}=-0.79$; 95\%CI: $-1.75,0.18 ; p=0.11)$. Meta-regression revealed that the differences in discharge rate between young and older adults increase with contraction intensity in upper body muscles $(\beta=-$ 0.033, $p=0.004)$. These findings suggest that motor function loss with aging might be partly explained by reduced motoneuron discharge rates; however, this decrease varies according to a muscle's anatomical location, functional role, and contraction intensity. 


\section{INTRODUCTION}

Aging is accompanied by a notable reduction in the ability to produce muscular force and power as well as a decline in the maximal rate of force development, which influences our capacity to perform physical activities of daily living (Bergland and Strand, 2019; Orssatto et al., 2020; Suetta et al., 2019; Tomás et al., 2018). These reductions are clearly observed after 50-60 years of age and the force, power and functional capacity losses accelerate during the subsequent decades of life (Larsson et al., 2019; Suetta et al., 2019; Vandervoort, 2002). Changes within the neuromuscular system have been investigated in order to understand the mechanisms underpinning the differences in force production across the lifespan (Hunter et al., 2016; Larsson et al., 2019; Manini et al., 2013; Orssatto et al., 2018). In addition to alterations within the muscles themselves, the role of neural factors needs to be clearly defined, given that muscle output will be limited by the neural input arriving from the motoneurons.

Both the number of recruited motor units and their discharge rates can be readily modulated by the central nervous system in order to regulate muscle forces; higher forces are achieved by an increase in the number of active motor units and/or their discharge rates (Enoka and Duchateau, 2017). The relative importance of motor unit recruitment versus discharge rate to the force rise differs significantly between muscles (De Luca and Kline, 2012) and important changes have been observed at the motor unit level during aging (Manini et al., 2013; Orssatto et al., 2018). Over at least the last four decades, researchers have investigated the effects of human aging on motor unit discharge rates during sustained isometric contractions (Kamen et al., 1995; Kirk et al., 2016; Mota et al., 2020; Nelson et al., 1983; Vaillancourt et al., 2003). However, inconsistent results have been observed when comparing young and older individuals, with some studies identifying lower (Christie and Kamen, 2010; Connelly et al., 1999; Gary Kamen and Knight, 2004; Kirk et al., 2019, 2018) but others similar mean discharge rates for a given proportional level of force during sustained isometric contractions (Christie 
and Kamen, 2009; Kallio et al., 2010; Kamen and Roy, 2000; Kirk et al., 2016). This inconsistency may be partly explained by the wide range of methods used across studies, with variations in the (i) muscles studied, often with them having distinct anatomical functions and locations (e.g., flexors/extensors and upper/lower body); and (ii) contraction intensities produced (2.5 to $100 \%$ of maximal voluntary force). Because of these differences, it has been difficult to draw broad conclusions based on data from any single study. In this case, a systematic review and analysis that pools the available data presented across studies could provide evidence that is more robust in relation to the effect of aging on motor unit discharge rates.

Given the above, the aim of the present systematic review and meta-analysis with metaregression is to identify and summarize the findings, and then estimate the effects, of studies comparing motor unit discharge rates between young and older participants during maximal and submaximal isometric sustained contractions. Thereafter, we discuss the potential influence of muscle anatomical location, functional role, and contraction intensity on differences in motor unit discharge rates between younger and older individuals.

\section{METHODS}

\subsection{Systematic search strategy}

A systematic literature search was conducted in three electronic databases (i.e., PubMed, Web of Sciences, and Scopus) in January 2020 and repeated in November 2020 (second search limited to articles published in 2020). The chosen search terms related to aging (e.g., age, elderly, older, and aging), motor units, and discharge rate (e.g., discharge rate, firing frequency, and inter-spike interval). The reference lists of the selected studies were screened for additional studies. The search procedures are reported in the Preferred Reporting Items for 
Systematic Reviews and Meta-Analyses (PRISMA) flow diagram (Liberati et al., 2009; Moher

et al., 2009) (Figure 1). The systematic search strategy was designed by LBRO and GST and conducted independently by LBRO and LP.

\subsection{Eligibility criteria}

Studies were selected according to the following inclusion criteria: i) compared groups based on age (young $=18-40$ years and elderly $\geq 60$ years); ii) adopted electromyographic methods allowing the identification of motor unit discharge rate; iii) discharge rate was measured during a sustained isometric contraction; iv) force level chosen for testing was based on a percentage of the each participant's maximal voluntary force; and v) peer-reviewed and published in English. Studies were excluded if they included participants with neurological (e.g., Parkinson disease, Alzheimer's) or musculoskeletal disorders (e.g., osteoarthritis, limb injury), involved explosive or dynamic contractions, or if data analyses or the test task were not clearly reported.

\subsection{Data extraction}

Data extracted from the selected studies included the country of the corresponding author, participant sample size, participants' characteristics and ages, muscles tested, relative force level reached during testing, and mean discharge rates for both young and older groups. For studies reporting chronic or acute intervention results (e.g., exercise training, fatiguing protocol, or visual gain) the baseline or control group/condition data were extracted. Data were converted to discharge rates for studies reporting inter-spike intervals. When data were reported in graphs, WebPlot Digitizer software (version 4.1) was used to extract the data. LBRO and LP conducted all data extraction independently before comparing results; mean variation between 
researchers was $<1 \%$. The mean values from data extracted by LBRO and LP were used for the analyses.

\subsection{Data analyses}

Our primary interest was to investigate whether differences in discharge rates exist between younger and older adults, with a specific focus on differences in lower body flexor muscles, lower body extensor muscles, and upper body muscles. A second interest was to examine the effect of contraction intensity on differences in motor unit discharge rates between younger and older adults.

Estimates from studies were combined within the meta-analysis using a random-effects model and presented as forest plots. The Hartung-Knapp-Sidik-Jonkman method was used as the estimator for the variance of the distribution of the true effect sizes, $\tau^{2}$ (Inthout et al., 2014). This estimator for $\tau^{2}$ method generally produces more conservative results (i.e., wider confidence intervals), particularly when the number of studies is small and between-study heterogeneity is large (Inthout et al., 2014). The standardised mean difference (SMD; Hedges' $g$ ) in motor unit discharge rates between younger and older adults was used because it was not always clear whether discharge rates were reported per motor unit or per participant.

Meta-regressions were used to determine the effect of contraction intensity on the SMD in discharge rates between younger and older adults. Separate models were run for lower body flexor muscles, lower body extensor muscles and upper body muscles; insufficient data existed to compare flexor and extensor muscles in the upper body. When studies examined differences across a range of contraction intensities, the effects were pooled for the meta-analysis. However, because pooled effects were not representative of any specific contraction intensity, non-pooled effects were used in the meta-regressions. 
The $I^{2}$ statistic was used to examine between-study heterogeneity, with higher values denoting greater heterogeneity (Higgins and Thompson, 2002). Where significant betweenstudy heterogeneity was observed, a Graphic Display of Heterogeneity plot was used to explore the patterns of heterogeneity. Sensitivity analysis was performed to determine the robustness of meta-estimates by comparing estimates before and after removing the single studies with the largest and smallest weights, respectively. Publication bias was evaluated using a funnel plot (Egger et al., 1997) and p-curve analysis (Simonsohn et al., 2014). Funnel plot asymmetry was examined using Egger's test of the intercept (Egger et al., 1997).

All analyses were conducted in $\mathrm{R}$ (version 4.0.3) using the RStudio environment (version 1.1.447) and the meta (Balduzzi et al., 2019), metafor (Viechtbauer, 2010) and dmetar (Harrer et al., 2019) packages. The $\alpha$ for all tests was set at 5\%. The data and $\mathrm{R}$ code that support the findings in this article can be accessed at https://github.com/orssatto/SRMA_MU.

\section{RESULTS}

\subsection{Systematic search}

The systematic search conducted in January 2020 retrieved 1056 studies and after duplicates removed, 945 study titles and abstracts were read for eligibility. After removing 890 studies, 55 studies were read in full and 30 were excluded according to the set criteria, resulting in 25 studies being included in the review. After repeating the search in November 2020, 73 studies were identified, 66 after duplicates removed, and no additional manuscript was included in the review. Figure 1 shows the PRISMA flow diagram for all steps of the systematic search. 

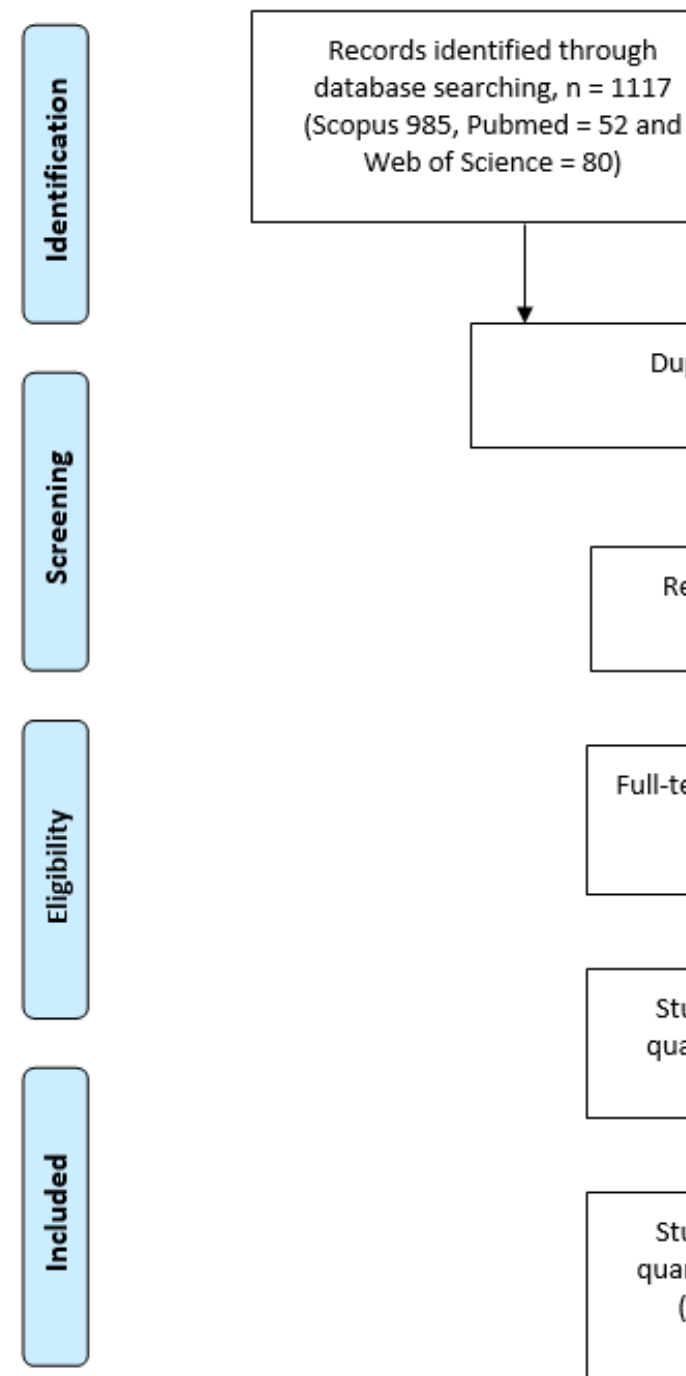

Records identified through

database searching, $\mathrm{n}=1117$

Web of Science $=80$ )

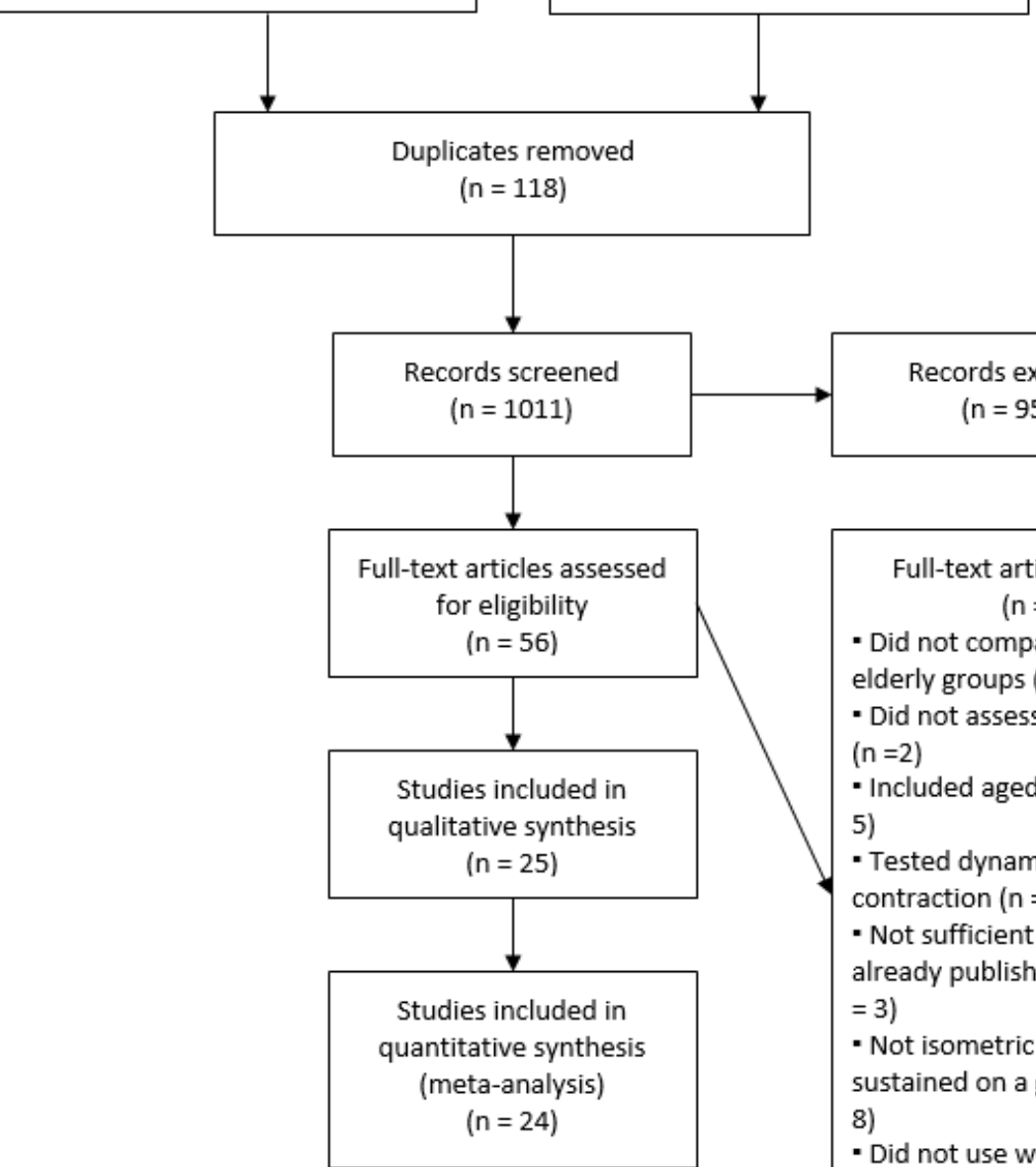

Records excluded

( $n=955)$

through other sources

$(n=12)$

$(n=31)$

- Did not compare young and

elderly groups $(n=2)$

- Did not assess discharge rate

( $n=2)$

- Included aged $<60$ years $(n=$

5)

- Tested dynamic or explosive

contraction $(n=1)$

- Not sufficient data or abstract already published elsewhere (n

$=3$ )

- Not isometric contraction

sustained on a given force $(n=$ 8)

- Did not use well defined \% of maximal force $(n=11)$

Figure 1. PRISMA flow diagram for the systematic search.

\subsection{Study characteristics}

Of the 25 included studies, 16 were conducted in the United States of America, 7 in Canada, 1 in Finland, and 1 in the United Kingdom. Studies tested a total of 303 young and 319 older participants. Different muscles were tested, including upper and lower body, flexors and extensors, and hand muscles. Most studies used intramuscular electromyography, except for four studies that used multichannel surface electromyography (5-pin electrodes, $\mathrm{n}=2$; and 
32- or 64-channel electrodes, $\mathrm{n}=2$ ). The contraction intensities ranged from $2.5 \%$ to $100 \%$ of the participants' maximal voluntary contraction forces.

\section{*Table 1 near here*}

\subsection{Meta-estimates}

Twenty-four studies were used for the meta-analysis, six of which examined lower body extensor muscles, seven examined lower body flexor muscles, and 11 examined upper body muscles. Kamen and Knight (2004) was not included in the meta-analysis, because we were unable to retrieve all necessary data. The pooled effects of the 24 studies are shown in Figure 2. There was evidence of differences in motor unit discharge rates between younger and older adults in lower body flexor muscles (SMD $=-0.86,95 \%$ CI: -1.20 to $-0.51, p<0.001)$, but not lower body extensor muscles (SMD $=-0.18,95 \% \mathrm{CI}$ : -0.50 to $0.15, p=0.29$ ) or upper body muscles (SMD $=-0.79,95 \% \mathrm{CI}:-1.75$ to $0.18, p=0.11)$.

There was significant between-study heterogeneity for investigations of upper body muscles $\left(I^{2}=74 \%, 95 \%\right.$ CI: $52 \%$ to $\left.86 \%, p<0.001\right)$. The Graphic Display of Heterogeneity plot (Supplementary material 1) indicated that this was largely attributed to three studies (Dalton et al., 2010; Kirk et al., 2019; Vaillancourt et al., 2003), and a marked reduction in heterogeneity $\left(I^{2}=11 \%, 95 \% \mathrm{CI}: 0 \%\right.$ to $\left.71 \%, p=.34\right)$ and decrease in the pooled mean effect $(\mathrm{SMD}=-0.35,95 \% \mathrm{CI}:-0.71$ to $0.01, p=.056)$ was found when these three studies were removed. 


\section{Subgroup}

(1) Lower Body Extensor Muscles Piasecki et al. (2016)

Dalton et al. (2009)

Kallio et al. (2010)

Kirk et al. (2016)

Mota et al. (2020)

Roos et al. (1999)

Random effects model

$I^{2}=0 \%[<0 \% ;<0 \%], \chi_{5}^{2}=0.7(p=0.98)$

(2) Lower Body Flexor Muscles

Kirk et al. (2018)

Rubinstein et al. (2005)

Connelly et al. (2000)

Patten et al. (2000)

Kwon et al. (2018)

Christie et al. (2010)

Christie et al. (2009)

Random effects model

$I^{2}=0 \%[0 \% ; 16 \%], \chi_{6}^{2}=2.09(p=0.91)$

\section{(3) Upper Body Muscles}

Dalton et al. (2010)

Kirk et al. (2019)

Kamen et al. (1995)

Erim et al. (1999)

Nelson et al. (1983)

Kamen et al. (2000)

Patten et al. (2001)

Pereira et al. (2019)

Feeney et al. (2018)

Laidlaw et al. (2000)

Vaillancourt et al. (2003)

Random effects model

$I^{2}=74 \%[52 \% ; 86 \%], \chi_{10}^{2}=38.26(p<0.01)$

Fixed effects (plural) model

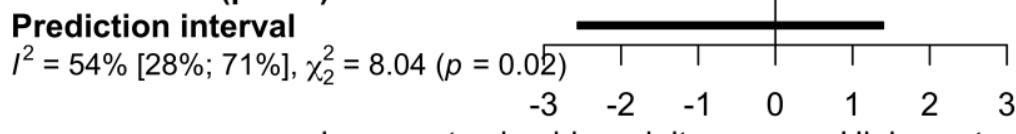

Standardised Mean Difference

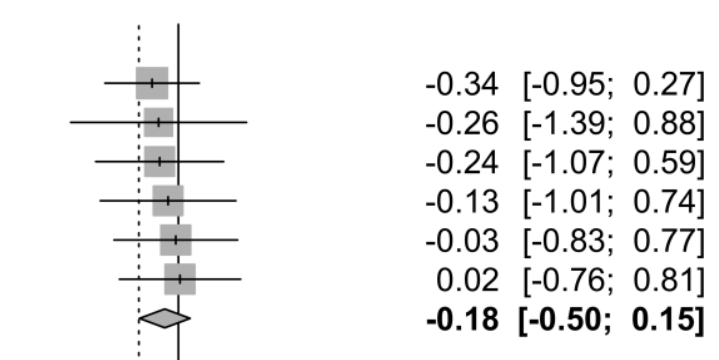

Lower rates in older adults
SMD $\quad 95 \% \mathrm{Cl}$

$-1.07[-2.00 ;-0.15]$

$-1.04[-2.03 ;-0.06]$

$-1.00[-2.23 ; 0.23]$

$-0.97[-2.19 ; 0.26]$

$-0.90[-1.76 ;-0.03]$

$-0.85[-1.38 ;-0.32]$

$-0.21[-1.20 ; 0.77]$

$-0.86[-1.20 ;-0.51]$

$-6.19[-9.42 ;-2.97]$

$-2.63[-3.90 ;-1.37]$

$-0.92[-2.05 ; 0.20]$

$-0.86 \quad[-1.78 ; 0.07]$

$-0.75[-1.42 ;-0.09]$

$-0.54 \quad[-1.58 ; 0.50]$

$-0.45[-1.60 ; 0.71]$

$-0.11 \quad[-0.54 ; 0.33]$

$0.12[-0.67 ; 0.90]$

$0.24 \quad[-0.64 ; 1.11]$

$0.54 \quad[-0.23 ; 1.32]$

$-0.79[-1.75 ; 0.18]$

$-0.51[-0.74 ;-0.28]$

$[-2.56 ; 1.40]$

Figure 2. Estimates of differences in motor unit discharge rates between younger and older adults in lower body extensor muscles, lower body flexor muscles, and upper body muscles. 


\subsection{Meta-regression}

Contraction intensity was statistically associated with effect size differences in upper body muscles $(\beta=-0.033, F=8.40, p=0.004$; Figure $3 \mathrm{C})$, with contraction intensity explaining $22 \%$ of the variability in the effect size data $\left(R^{2}=21.9 \%\right)$. Contraction intensity was not significantly associated with effect size differences in the lower body extensor $(\beta=0.001, F=$ $0.04, p=.84, R^{2}=00.0 \%$; Figure $\left.3 \mathrm{~A}\right)$ or flexor $\left(\beta=-0.006, F=1.96, p=0.16, R^{2}=11.9 \%\right.$; Figure 3B) models. Notably, these associations remained unchanged when a single metaregression model was fitted, with contraction intensity, subgroup and contraction intensity by subgroup included as predictor variables. 
(A) Lower Body Extensor Muscles

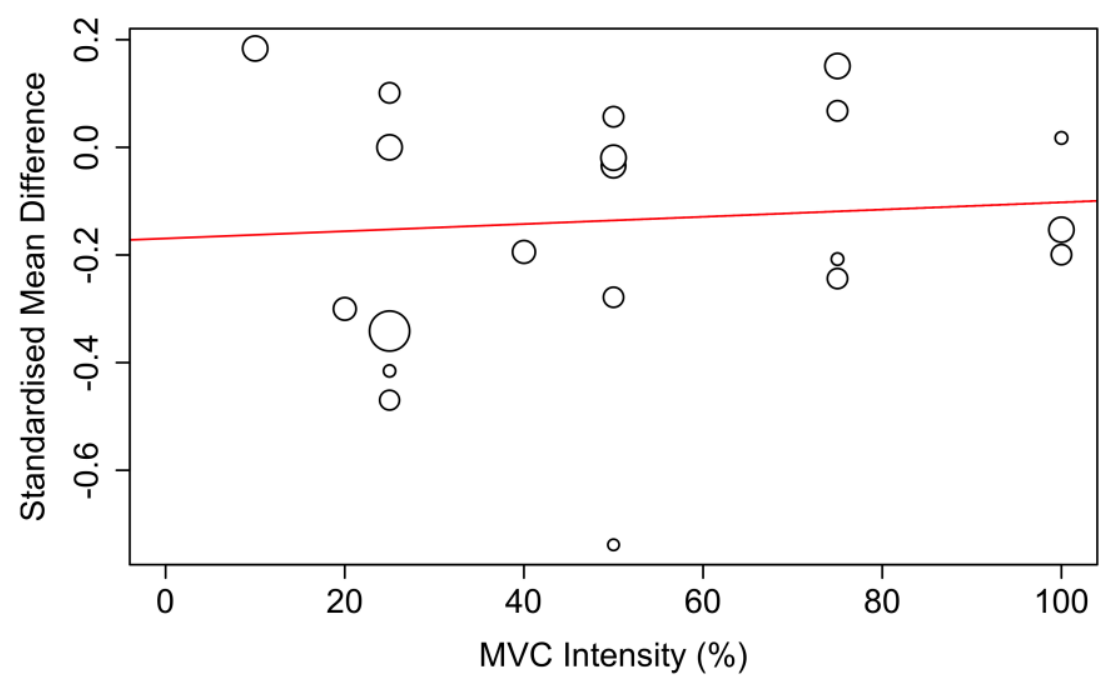

(B) Lower Body Flexor Muscles

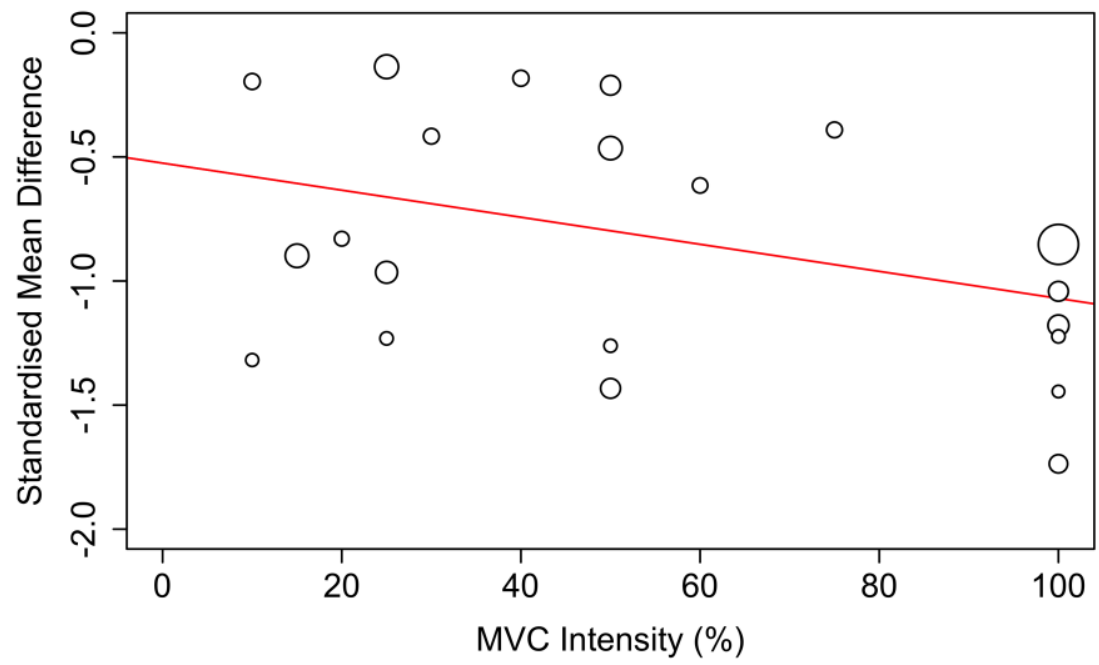

(C) Upper Body Muscles

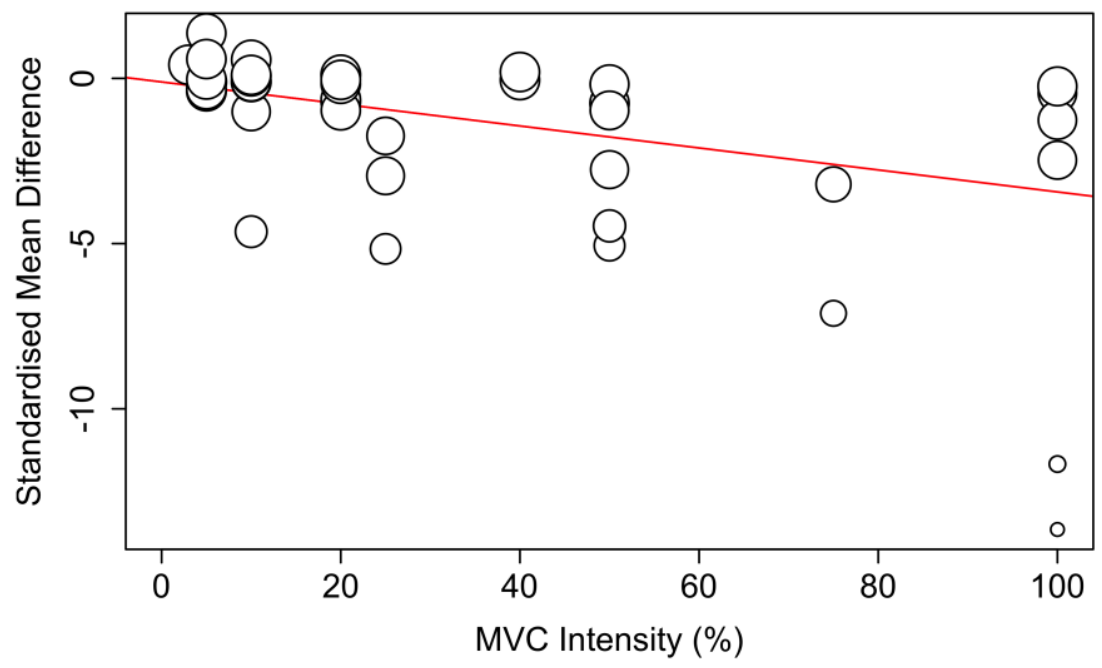


Figure 3. Bubble plots with fitted meta-regression lines indicating the effect of contraction intensity on the standardised mean difference in motor unit discharge rates between younger and older adults in lower body extensor (A), lower body flexor (B), and upper body (C) muscles. The size of each point is inversely proportional to the variance of the estimated difference. Negative standardised mean differences indicate lower discharge rates in older adults.

\subsection{Sensitivity analysis}

Table 2 shows the results from the sensitivity analysis. The pooled SMD changed only marginally after removing the study with the largest weight, except for the upper body muscles subgroup in which the removal of Dalton et al., (2010) resulted in a marked SMD change from -0.79 (95\% CI: -1.75 to 0.18 ) to -0.46 (95\% CI: -1.00 to 0.08 ). Removing the study with the smallest weight resulted in only marginal SMD change for lower body flexor and extensor muscles. In contrast, removing the study by Vaillancourt et al. (2003) resulted in a marked SMD change for upper body muscles, from -0.79 (95\% CI: -1.75 to 0.18$)$ to -0.93 (95\% CI: 1.96 to 0.09$)$.

Table 2. Results of the sensitivity analysis.

\begin{tabular}{lccc}
\hline \multirow{2}{*}{ Subgroups } & All studies included & $\begin{array}{c}\text { Study with the largest } \\
\text { weight excluded }\end{array}$ & $\begin{array}{c}\text { Study with the smallest } \\
\text { weight excluded }\end{array}$ \\
\cline { 2 - 4 } & \multicolumn{3}{c}{ Pooled standardised mean difference [95\% CI] } \\
\hline $\begin{array}{l}\text { Lower body extensor } \\
\text { muscles }\end{array}$ & $-0.18[-0.50,0.15]$ & $-0.11[-0.50,0.28]$ & $-0.22[-0.58,0.14]$ \\
$\begin{array}{l}\text { Lower body flexor } \\
\text { muscles }\end{array}$ & $-0.86[-1.20,-0.51]$ & $-0.82[-1.20,-0.45]$ & $-0.93[-1.28,-0.59]$ \\
Upper body muscles & $-0.79[-1.75,0.18]$ & $-0.46[-1.00,0.08]$ & $-0.93[-1.96,0.09]$ \\
\hline
\end{tabular}

Note: $\mathrm{CI}=$ Confidence interval 


\subsection{Publication bias}

Supplement material 2 shows the funnel plot. Egger's test indicated the presence of asymmetry in the funnel plot (intercept $=-2.23,95 \%$ CI: -3.88 to $-0.59 ; t=-2.66 ; p=.014$ ), which may have been caused by publication bias, when studies with small samples and small effect sizes are missing. However, the $p$-curve was right-skewed (Supplement 3), indicating that there was a 'true' effect underlying the findings and that the results were most likely not the result of publication bias alone.

\section{DISCUSSION}

\subsection{Main findings}

The present meta-analytic review interrogated the current literature to determine the effects of aging on motor unit discharge rates. We summarised the findings of studies comparing motor unit discharge rates between young and older adult participants during sustained maximal and submaximal isometric contractions. We also attempted to determine the influence of contraction intensity and both muscle anatomical location and functional role on motor unit discharge rates during aging. The main findings were that the reductions in motor unit discharge rates at a given relative force level might depend on the muscle anatomical location, functional role, and contraction intensity. Older adults produced lower discharge rates than young adults in lower body flexor muscles but not in lower body extensors or upper body muscles. However, high between-study heterogeneity was observed for upper body muscles. Also, an influence of contraction intensity on the difference between younger and older adults was also observed for upper body muscles. Likewise, discharge rates at MVC were also lower in older adults. These results show why inconsistent results have been observed in the extant literature as to the effects of aging on motor unit discharge rates, and they thus contribute to 
our understanding of the effects of aging on neural control during sustained isometric submaximal and maximal contractions.

\subsection{The effect of muscle anatomical location and function on discharge rate differences between young and older adults}

Age-dependent differences in discharge rates are not readily apparent in studies in which lower limb extensor or upper limb muscles were studied but are clear in studies of lower limb flexor muscles. The effect of aging on discharge rates therefore appears to be specific to a muscle's anatomical location (upper vs. lower body) and function (extensor vs. flexor). Differences between muscles of different anatomical location might speculatively be explained by the characteristics of the descending tracts that innervate these muscle groups (Taylor et al., 2000). For example, previous studies in the ventral spinal cord of the decerebrate cat and neonatal rat as well as estimations of motoneuron excitability in humans have shown a greater excitability of extensor than flexor motoneurons (Cotel et al., 2009; Hounsgaard et al., 1988; Wilson et al., 2015). Lower body extensors commonly serve an anti-gravity role, meaning that they are active for longer periods and produce greater cumulative force than flexor muscles during activities of daily living, including during upright standing and locomotor propulsion (e.g., walking) (Masani et al., 2013; Soames and Atha, 1981). These functions may be associated with a lesser risk of discharge rate loss with aging. Additional evidence for this assertion is provided by the findings that, while disuse can aggravate the deleterious effects of aging on the nervous system, master-level (i.e. older adult) athletes show a substantial preservation of neural function (Aagaard et al., 2010; Hvid et al., 2018; McGregor et al., 2011; Unhjem et al., 2016). 


\subsection{The role of contraction intensity on discharge rate differences between young and older adults}

We also examined whether stronger contraction levels might exacerbate age-dependent differences in motor unit discharge rates through use of meta-regression analyses. The results showed a statistical effect of contraction intensity on discharge rate differences only for studies investigating upper body muscles (Figure 3C). However, it should be pointed out that there was a notable effect of intensity on the difference in discharge rates in lower body flexor muscles $(\beta=-0.006, p=0.16$; Figure 3B), despite statistical significance not being reached; that is, there was a mean reduction in discharge rates with aging, with the propensity for greater reduction at higher contraction intensities. For context, at a contraction intensity of $50 \% \mathrm{MVC}$, intensity alone accounted for (SMD) -0.3 of the difference between younger and older adults. Also, Figure 3 shows a clear lower discharge rate for older adults during maximal contractions for upper body and lower body flexors. Nonetheless, no contraction intensity influence was observed in lower body extensor muscles.

The reduction of discharge rates during maximal contractions is likely a factor resulting in the reduced and more variable muscle voluntary activation level observed in older adults (Jakobi and Rice, 2002; Rozand et al., 2020). Discharge rate declines may also underpin compression of the range of discharge rates observed in older adults (Barry et al., 2007). The reduction in discharge rates, particularly at high contraction levels, might reflect both functional and structural changes within the nervous system. Hypothetically, mechanisms contributing to a potential motoneuron discharge rate reduction may include i) the motoneuron's intrinsic characteristics, which affects their recruitment threshold (Heckman and Enoka, 2012; Piotrkiewicz and Türker, 2017); and ii) the effect of neuromodulation on motoneuron excitability (Heckman et al., 2009; Johnson and Heckman, 2014). 
At the motoneuron level, several age-related structural and functional changes may explain the greater reduction in motoneuron discharge rate in higher-force contractions. Central to this is that motoneurons are affected by axonal demyelination, atrophy and degeneration during aging (Jang and Remmen, 2011; McKinnon et al., 2015; Misgeld, 2011; Selman et al., 2012). This motoneuron deterioration can trigger muscle fibre denervation, resulting in some fibres being unable to contribute to force production (Aare et al., 2016). Whilst a compensatory mechanism allows low-threshold motoneurons to reinnervate some nearby denervated type II muscle fibres (Hepple and Rice, 2015), it does not prevent the reduction in motor unit discharge rate since the lower-threshold reinnervating motoneuron will exhibit slower discharge rates (Deschenes, 2011; Piasecki et al., 2016). As a result, older adults have fewer (McNeil et al., 2005; Mittal and Logmani, 1987; Tomlinson and Irving, 1977) but larger MUs, a greater proportion of which are innervated by low-threshold motoneurons (Dalton et al., 2008; Lexell and Taylor, 1991). Although debate exists (Piotrkiewicz and Türker, 2017), motor units innervated by higher recruitment-threshold motoneurons should discharge at higher rates during contractions close to maximal force. However, at lower contraction intensities, motor units innervated by lower threshold motoneurons typically discharge at higher rates than those innervated by higher threshold neurons, which typically start to discharge at higher rates as force level increases (Hu et al., 2014; Oya et al., 2009). As older adults typically possess fewer higher threshold motoneuron, this might explain the lower rate relative to younger adults at higher intensities contractions in lower body flexor and upper body muscles.

Motoneuron discharge rates are also influenced by neuromodulatory inputs (i.e., serotonin and noradrenalin) from the monoaminergic system, which affects motoneuron intrinsic excitability. Monoamines exert strong facilitation onto motoneurons by triggering persistent inward calcium and sodium currents, and reducing recruitment thresholds by increased conductance and reduced amplitude and duration of the afterhyperpolarisation when 
PICs are strongly active (Heckman et al., 2008; Lee and Heckman, 1999, 1998). Reduced serotonin concentrations (Ko et al., 1997), axonal degeneration in serotonergic neurons (Johnson et al., 1993), and a decline in the activity of noradrenergic neurons emanating from the locus coeruleus (the primary source of noradrenalin-releasing axons in the spinal cord) (Olpe and Steinmann, 1982; Vijayashankar and Brody, 1979) suggest that aging negatively affects the monoaminergic system. Therefore, older adults should have an impaired ability to facilitate motoneuron excitability, although experiments exploring these mechanisms are yet to be performed in humans. Also, some evidence indicates that motoneurons of older adults exhibit greater afterhyperpolarisation duration (Piotrkiewicz et al., 2007), which indicate a reduced net excitability. Taken together, the smaller number and proportion of higher-threshold motoneurons as well as an impaired neuromodulation that could limit motoneuron excitability may collectively limit motoneuron discharge rates during high-intensity, more than lowintensity, contractions.

\subsection{Limitations}

Despite the relevance of the current findings, some limitations should be mentioned. First, our search only identified studies conducted in developed countries (i.e., USA, Canada, Finland, and United Kingdom). It is unclear if, for example, whether the potentially longer life expectancy and better physical health in individuals from developed countries might influence the research findings. Also, studies investigating sex-related effects of aging on motor unit discharge rates are lacking. Only one study (Pereira et al., 2019) compared older and younger men and women, whilst other studies only tested men, combined male and female data, or did not report the participants' sex (Table 1). Thus, it was not possible to explore potential sexrelated differences on motor unit discharge rate reductions during aging; future studies are 
clearly warranted to address this issue. Another important limitation of the literature is the small number of studies investigating upper body flexor (Dalton et al., 2010; Pereira et al., 2019) and extensor muscles (Pereira et al., 2019), which did not allow meta-analysis to be used to compare these muscle groups. In the upper body, most studies tested muscles located in the hand or shoulder girdle (trapezius). Also, only studies adopting sustained isometric contractions and in which motor unit discharge rates were measured during the contraction plateau were included in our systematic search. This methodological restriction allowed a better control for between-study comparisons because motor unit discharge behaviour is contraction mode dependent (i.e., isometric vs. concentric vs. eccentric) and varies with movement velocity (i.e., fast or slow) and the phase of isometric force production (i.e., torque rise, plateau or decline). However, this inclusion criterion could mask some potential age-related differences that may occur in other contractions or movement tasks. For example, evidence exists that motor unit discharge rates during explosive contractions may be more sensitive to aging (Klass et al., 2008); however, more studies are required before clear conclusions can be drawn. Therefore, our findings may only be reflective of those during isometric contractions.

\section{CONCLUSIONS}

The present systematic review identified 25 studies reporting mixed results regarding the differences in motor unit discharge rates during sustained isometric contractions between young and older adults. Several patterns regarding age-related reductions in discharge rate were identified. In upper body muscles, no significant differences were observed between young and older adults. Lower body extensor muscles discharge rates also seem to be maintained in older adults, however lower body flexor discharge rates were markedly reduced, irrespective of contraction intensity. These data suggest that discharge rates are only consistently reduced in 
some muscles, whilst discharge rate is preserved in others. Identifying the factors underpinning the retention of discharge rate may be important to develop methods to retain discharge rate in other muscles, such as the lower body flexor muscles. Further, a greater difference in discharge rates for young and older adults has been observed for higher contraction intensities in upper body muscles. Interpretation for upper body muscles data should be made with some caution because between-study heterogeneity was high; particularly in higher intensity contractions, and differences could potentially range from negligible to large.

It is important to consider that these findings may only be reflective of motor unit behaviour during isometric contractions. There was also considerable methodological heterogeneity among studies regarding the muscles examined, contraction intensities used, discharge rate measurement techniques, and the age-range of participants. These aspects of study design require careful consideration by future investigations. 


\section{REFERENCES}

Aagaard, P., Suetta, C., Caserotti, P., Magnusson, S.P., Kjær, M., 2010. Role of the nervous system in sarcopenia and muscle atrophy with aging: Strength training as a countermeasure. Scand. J. Med. Sci. Sport. 20, 49-64.

Aare, S., Spendiff, S., Vuda, M., Elkrief, D., Perez, A., Wu, Q., Mayaki, D., Hussain, S.N.A., Hettwer, S., Hepple, R.T., 2016. Failed reinnervation in aging skeletal muscle. Skelet. Muscle 6, 29. https://doi.org/10.1186/s13395-016-0101-y

Balduzzi, S., Rücker, G., Schwarzer, G., 2019. How to perform a meta-analysis with R: A practical tutorial. Evid. Based. Ment. Health 22, 153-160. https://doi.org/10.1136/ebmental-2019-300117

Barry, B.K., Pascoe, M.A., Jesunathadas, M., Enoka, R.M., 2007. Rate coding is compressed but variability is unaltered for motor units in a hand muscle of old adults. J. Neurophysiol. 97, 3206-3218. https://doi.org/10.1152/jn.01280.2006

Bergland, A., Strand, B.H., 2019. Norwegian reference values for the Short Physical Performance Battery (SPPB): The Troms $\varnothing$ Study. BMC Geriatr. 19, 1-10. https://doi.org/10.1186/s12877-019-1234-8

Christie, A., Kamen, G., 2010. Short-term training adaptations in maximal motor unit firing rates and afterhyperpolarization duration. Muscle and Nerve 41, 651-660. https://doi.org/10.1002/mus.21539

Christie, A., Kamen, G., 2009. Motor unit firing behavior during prolonged 50\% MVC dorsiflexion contractions in young and older adults. J. Electromyogr. Kinesiol. 19, 543552. https://doi.org/10.1016/j.jelekin.2008.03.005

Connelly, D.M., Rice, C.L., Roos, M.R., Vandervoort, A.A., 1999. Motor unit firing rates and 
contractile properties in tibialis anterior of young and old men. J. Appl. Physiol. 87, 843-852. https://doi.org/10.1152/jappl.1999.87.2.843

Cotel, F., Antri, M., Barthe, J.Y., Orsal, D., 2009. Identified ankle extensor and flexor motoneurons display different firing profiles in the neonatal rat. J. Neurosci. 29, 2748 2753. https://doi.org/10.1523/JNEUROSCI.3462-08.2009

Dalton, B.H., Harwood, B., Davidson, A.W., Rice, C.L., 2009. Triceps surae contractile properties and firing rates in the soleus of young and old men. J. Appl. Physiol. 107, 1781-1788. https://doi.org/10.1152/japplphysiol.00464.2009

Dalton, B.H., Jakobi, J.M., Allman, B.L., Rice, C.L., 2010. Differential age-related changes in motor unit properties between elbow flexors and extensors. Acta Physiol. 200, 45-55. https://doi.org/10.1111/j.1748-1716.2010.02100.x

Dalton, B.H., McNeil, C.J., Doherty, T.J., Rice, C.L., 2008. Age-related reductions in the estimated numbers of motor units are minimal in the human soleus. Muscle and Nerve 38, 1108-1115. https://doi.org/10.1002/mus.20984

De Luca, C.J., Kline, J.C., 2012. Influence of proprioceptive feedback on the firing rate and recruitment of motoneurons. J. Neural Eng. 9. https://doi.org/10.1088/17412560/9/1/016007

Deschenes, M.R., 2011. Motor unit and neuromuscular junction remodeling with aging. Curr. Aging Sci. 4, 209-20.

Egger, M., Davey Smith, G., Schneider, M., Minder, C., 1997. Bias in meta-analysis detected by a simple, graphical test. BMJ 315, 629-34. https://doi.org/10.1136/bmj.315.7109.629

Enoka, R.M., Duchateau, J., 2017. Rate coding and the control of muscle force. Cold Spring Harb. Perspect. Med. 7. https://doi.org/10.1101/cshperspect.a029702 
Erim, Z., Beg, M.F., Burke, D.T., De Luca, C.J., 1999. Effects of aging on motor-unit control properties. J. Neurophysiol. 82, 2081-2091. https://doi.org/10.1152/jn.1999.82.5.2081

Feeney, D.F., Mani, D., Enoka, R.M., 2018. Variability in common synaptic input to motor neurons modulates both force steadiness and pegboard time in young and older adults. J. Physiol. 596, 3793-3806. https://doi.org/10.1113/JP275658

Harrer, M., Cuijpers, P., Furukawa, T., Ebert, D.D., 2019. dmetar: Companion R Package For The Guide "Doing Meta-Analysis in R". R package version 0.0.9000.

Heckman, C.J., Enoka, R.M., 2012. Motor unit. Compr. Physiol. 2, 2629-2682. https://doi.org/10.1002/cphy.c100087

Heckman, C.J., Johnson, M., Mottram, C., Schuster, J., 2008. Persistent inward currents in spinal motoneurons and their influence on human motoneuron firing patterns. Neuroscientist 14, 264-275. https://doi.org/10.1177/1073858408314986

Heckman, C.J., Mottram, C., Quinlan, K., Theiss, R., Schuster, J., 2009. Motoneuron excitability: The importance of neuromodulatory inputs. Clin. Neurophysiol. 120, 20402054. https://doi.org/10.1016/j.clinph.2009.08.009

Hepple, R.T., Rice, C.L., 2015. Innervation and neuromuscular control in ageing skeletal muscle. J. Physiol. 00, 1-14. https://doi.org/10.1113/jp270561

Higgins, J.P.T., Thompson, S.G., 2002. Quantifying heterogeneity in a meta-analysis. Stat. Med. 21, 1539-1558. https://doi.org/10.1002/sim.1186

Hounsgaard, J., Hultborn, H., Jespersen, B., Kiehn, O., 1988. Bistability of alphamotoneurones in the decerebrate cat and in the acute spinal cat after intravenous 5hydroxytryptophan. J. Physiol. 405, 345-367. https://doi.org/10.1113/jphysiol.1988.sp017336 
Hu, X., Rymer, W.Z., Suresh, N.L., 2014. Motor unit firing rate patterns during voluntary muscle force generation: A simulation study. J. Neural Eng. 11. https://doi.org/10.1088/1741-2560/11/2/026015

Hunter, S.K., Pereira, X.H.M., Keenan, K.G., 2016. The aging neuromuscular system and motor performance. J. Appl. Physiol. 121, 982-995. https://doi.org/10.1152/japplphysiol.00475.2016

Hvid, L.G., Aagaard, P., Ørtenblad, N., Kjaer, M., Suetta, C., 2018. Plasticity in central neural drive with short-term disuse and recovery - effects on muscle strength and influence of aging. Exp. Gerontol. 106, 145-153. https://doi.org/10.1016/j.exger.2018.02.019

Inthout, J., Ioannidis, J.P., Borm, G.F., 2014. The Hartung-Knapp-Sidik-Jonkman method for random effects meta-analysis is straightforward and considerably outperforms the standard DerSimonian-Laird method. BMC Med. Res. Methodol. 14, 1-12. https://doi.org/10.1186/1471-2288-14-25

Jakobi, J.M., Rice, C.L., 2002. Voluntary muscle activation varies with age and muscle group. J. Appl. Physiol. 93, 457-462. https://doi.org/10.1152/japplphysiol.00012.2002

Jang, Y.C., Remmen, H. Van, 2011. Age-associated alterations of neuromuscular junction. Exp. Gerontol. 46, 193-198. https://doi.org/10.1016/j.exger.2010.08.029.Age-associated Johnson, H., Ulfhake, B., Dagerlind, Å., Bennett, G.W., Fone, K.C.F., Hökfelt, T., 1993. The serotoninergic bulbospinal system and brainstern-spinal cord content of serotonin-, TRH-, and substance P-like immunoreactivity in the aged rat with special reference to the spinal cord motor nucleus. Synapse 15, 63-89. https://doi.org/10.1002/syn.890150108 
Johnson, M.D., Heckman, C.J., 2014. Gain control mechanisms in spinal motoneurons. Front. Neural Circuits 8, 1-7. https://doi.org/10.3389/fncir.2014.00081

Kallio, J., Avela, J., Moritani, T., Kanervo, M., Selänne, H., Komi, P., Linnamo, V., 2010. Effects of ageing on motor unit activation patterns and reflex sensitivity in dynamic movements. J. Electromyogr. Kinesiol. 20, 590-598. https://doi.org/10.1016/j.jelekin.2009.12.005

Kamen, Gary, Knight, C.A., 2004. Training-related adaptations in motor unit discharge rate in young and older adults. Journals Gerontol. - Ser. A Biol. Sci. Med. Sci. 59, 13341338. https://doi.org/10.1093/gerona/59.12.1334

Kamen, G, Knight, C.A., 2004. Training-related adaptations in motor unit discharge rate in young and older adults. J Gerontol A Biol Sci Med Sci 59, 1334-1338.

Kamen, G., Roy, A., 2000. Motor unit synchronization in young and elderly adults. Eur. J. Appl. Physiol. 81, 403-410. https://doi.org/10.1007/s004210050061

Kamen, G., Sison, S. V., Du, C.C.D., Patten, C., 1995. Motor unit discharge behavior in older adults during maximal-effort contractions. J. Appl. Physiol. 79, 1908-1913. https://doi.org/10.1152/jappl.1995.79.6.1908

Kirk, E.A., Copithorne, D.B., Dalton, B.H., Rice, C.L., 2016. Motor unit firing rates of the gastrocnemii during maximal and sub-maximal isometric contractions in young and old men. Neuroscience 330, 376-385. https://doi.org/10.1016/j.neuroscience.2016.05.059

Kirk, E.A., Gilmore, K.J., Rice, C.L., 2018. Neuromuscular changes of the aged human hamstrings. J. Neurophysiol. 120, 480-488. https://doi.org/10.1152/jn.00794.2017

Kirk, E.A., Gilmore, K.J., Stashuk, D.W., Doherty, T.J., Rice, C.L., 2019. Human motor unit characteristics of the superior trapezius muscle with age-related comparisons. J. 
Neurophysiol. 122, 823-832. https://doi.org/10.1152/jn.00138.2019

Klass, M., Baudry, S., Duchateau, J., 2008. Age-related decline in rate of torque development is accompanied by lower maximal motor unit discharge frequency during fast contractions. J. Appl. Physiol. 104, 739-746.

https://doi.org/10.1152/japplphysiol.00550.2007

Ko, M.L., King, M.A., Gordon, T.L., Crisp, T., 1997. The effects of aging on spinal neurochemistry in the rat. Brain Res. Bull. 42, 95-98. https://doi.org/10.1016/S03619230(96)00216-X

Kwon, M., Christou, E.A., 2018. Visual information processing in older adults: Reaction time and motor unit pool modulation. J. Neurophysiol. 120, 2630-2639. https://doi.org/10.1152/jn.00161.2018

Laidlaw, D.H., Bilodeau, M., Enoka, R.M., 2000. Steadiness is reduced and motor unit discharge is more variable in old adults. Muscle and Nerve 23, 600-612. https://doi.org/10.1002/(SICI)1097-4598(200004)23:4<600::AID-MUS20>3.0.CO;2-D

Larsson, L., Degens, H., Li, M., Salviati, L., Lee, Y. il, Thompson, W., Kirkland, J.L., Sandri, M., 2019. Sarcopenia: Aging-Related Loss of Muscle Mass and Function. Physiol. Rev. 99, 427-511. https://doi.org/10.1152/physrev.00061.2017

Lee, R.H., Heckman, C.J., 1999. Enhancement of bistability in spinal motoneurons in vivo by the noradrenergic $\alpha 1$ agonist methoxamine. J. Neurophysiol. 81, 2164-2174. https://doi.org/10.1152/jn.1999.81.5.2164

Lee, R.H., Heckman, C.J., 1998. Bistability in spinal motoneurons in vivo: Systematic variations in rhythmic firing patterns. J. Neurophysiol. 80, 572-582. https://doi.org/10.1152/jn.1998.80.2.572 
Lexell, J., Taylor, C.C., 1991. Variability in muscle fibre areas in whole human quadriceps muscle: effects of increasing age. J. Anat. 174, 239-49.

Liberati, A., Altman, D.G., Tetzlaff, J., Mulrow, C., Gøtzsche, P.C., Ioannidis, J.P.A., Clarke, M., Devereaux, P.J., Kleijnen, J., Moher, D., 2009. The PRISMA Statement for Reporting Systematic Reviews and Meta-Analyses of Studies That Evaluate Health Care Interventions : Explanation and Elaboration. PLoS Med. 6. https://doi.org/10.1371/journal.pmed.1000100

Manini, T.M., Hong, S.L., Clark, B.C., 2013. Aging and muscle: a neuron's perspective. Curr. Opin. Clin. Nutr. Metab. Care 16, 1-10. https://doi.org/10.1097/MCO.0b013e32835b5880.Aging

Masani, K., Sayenko, D.G., Vette, A.H., 2013. What triggers the continuous muscle activity during upright standing? Gait Posture 37, 72-77. https://doi.org/10.1016/j.gaitpost.2012.06.006

McGregor, K.M., Zlatar, Z., Kleim, E., Sudhyadhom, A., Bauer, A., Phan, S., Seeds, L., Ford, A., Manini, T.M., White, K.D., Kleim, J., Crosson, B., 2011. Physical activity and neural correlates of aging: A combined TMS/fMRI study. Behav. Brain Res. 222, 158168. https://doi.org/10.1016/j.bbr.2011.03.042

McKinnon, N.B., Montero-Odasso, M., Doherty, T.J., 2015. Motor unit loss is accompanied by decreased peak muscle power in the lower limb of older adults. Exp. Gerontol. 70, 111-118. https://doi.org/10.1016/j.exger.2015.07.007

Misgeld, T., 2011. Lost in elimination: mechanisms of axonal loss. e-Neuroforum 2, 21-34. https://doi.org/10.1007/s13295-011-0017-2

Moher, D., Liberati, A., Tetzlaff, J., Altman, D.G., Altman, D., Antes, G., Atkins, D., 
Barbour, V., Barrowman, N., Berlin, J.A., Clark, J., Clarke, M., Cook, D., D’Amico, R.,

Deeks, J.J., Devereaux, P.J., Dickersin, K., Egger, M., Ernst, E., Gøtzsche, P.C.,

Grimshaw, J., Guyatt, G., Higgins, J., Ioannidis, J.P.A., Kleijnen, J., Lang, T., Magrini, N., McNamee, D., Moja, L., Mulrow, C., Napoli, M., Oxman, A., Pham, B., Rennie, D., Sampson, M., Schulz, K.F., Shekelle, P.G., Tovey, D., Tugwell, P., 2009. Preferred reporting items for systematic reviews and meta-analyses: The PRISMA statement. PLoS Med. 6. https://doi.org/10.1371/journal.pmed.1000097

Mota, J.A., Kwon, D.P., Kennedy, M., Sobolewski, E.J., Kim, Y., Gonzales, J.U., Stock, M.S., 2020. Compensatory adjustments in motor unit behavior during fatigue differ for younger versus older men. Aging Clin. Exp. Res. https://doi.org/10.1007/s40520-01901438-6

Nelson, R.M., Soderberg, G.L., Urbscheit, N.L., 1983. Comparison of skeletal muscle motor unit discharge characteristics in young and aged humans. Arch. Gerontol. Geriatr. 2, 255-264. https://doi.org/10.1016/0167-4943(83)90029-8

Olpe, H.R., Steinmann, M.W., 1982. Age-related decline in the activity of noradrenergic neurons of the rat locus coeruleus. Brain Res. 251, 174-176. https://doi.org/10.1016/0006-8993(82)91287-2

Orssatto, L.B. da R., Bezerra, E. de S., Schoenfeld, B.J., Diefenthaeler, F., 2020. Lean, fast and strong: Determinants of functional performance in the elderly. Clin. Biomech. Ahead of p, 103182. https://doi.org/10.1016/j.clinbiomech.2020.105073

Orssatto, L.B. da R., Wiest, M.J., Diefenthaeler, F., 2018. Neural and musculotendinous mechanisms underpinning age-related force reductions. Mech. Ageing Dev. 175, 17-23. https://doi.org/10.1016/j.mad.2018.06.005

Oya, T., Riek, S., Cresswell, A.G., 2009. Recruitment and rate coding organisation for soleus 
motor units across entire range of voluntary isometric plantar flexions. J. Physiol. 587, 4737-4748. https://doi.org/10.1113/jphysiol.2009.175695

Patten, C., Kamen, G., 2000. Adaptations in motor unit discharge activity with force control training in young and older human adults. Eur. J. Appl. Physiol. 83, 128-143. https://doi.org/10.1007/s004210000271

Patten, C., Kamen, G., Rowland, D.M., 2001. Adaptations in maximal motor unit discharge rate to strength training in young and older adults. Muscle and Nerve 24, 542-550. https://doi.org/10.1002/mus.1038

Pereira, H.M., Schlinder-DeLap, B., Keenan, K.G., Negro, F., Farina, D., Hyngstrom, A.S., Nielson, K.A., Hunter, S.K., 2019. Oscillations in neural drive and age-related reductions in force steadiness with a cognitive challenge. J. Appl. Physiol. 126, 10561065. https://doi.org/10.1152/japplphysiol.00821.2018

Piasecki, Mathew, Ireland, A., Jones, D.A., McPhee, J.S., 2016. Age-dependent motor unit remodelling in human limb muscles. Biogerontology 17, 485-496. https://doi.org/10.1007/s10522-015-9627-3

Piasecki, M., Ireland, A., Stashuk, D., Hamilton-Wright, A., Jones, D.A., McPhee, J.S., 2016. Age-related neuromuscular changes affecting human vastus lateralis. J. Physiol. 594, 4525-4536. https://doi.org/10.1113/JP271087

Piotrkiewicz, M., Kudina, L., Mierzejewska, J., Jakubiec, M., Hausmanowa-petrusewicz, I., 2007. Age-related change in duration of afterhyperpolarization of human motoneurones. J. Physiol. 585, 483-490. https://doi.org/10.1113/jphysiol.2007.142356

Piotrkiewicz, M., Türker, K.S., 2017. Onion skin or common drive? Front. Cell. Neurosci. 11, 2015-2018. https://doi.org/10.3389/fncel.2017.00002 
Roos, M.R., Rice, C.L., Connelly, D.M., Vandervoort, A.A., 1999. Quadriceps muscle strength, contractile properties, and motor unit firing rates in young and old men. Muscle and Nerve 22, 1094-1103. https://doi.org/10.1002/(SICI)10974598(199908)22:8<1094::AID-MUS14>3.0.CO;2-G

Rozand, V., Sundberg, C.W., Hunter, S.K., Smith, A.E., 2020. Age-related Deficits in Voluntary Activation: A Systematic Review and Meta-analysis. Med. Sci. Sports Exerc. 52, 549-560. https://doi.org/10.1249/MSS.0000000000002179

Rubinstein, S., Kamen, G., 2005. Decreases in motor unit firing rate during sustained maximal-effort contractions in young and older adults. J. Electromyogr. Kinesiol. 15, 536-543. https://doi.org/10.1016/j.jelekin.2005.04.001

Selman, C., Blount, J.D., Nussey, D.H., Speakman, J.R., 2012. Oxidative damage, ageing, and life-history evolution: Where now? Trends Ecol. Evol. 27, 570-577. https://doi.org/10.1016/j.tree.2012.06.006

Simonsohn, U., Nelson, L.D., Simmons, J.P., 2014. p-Curve and Effect Size: Correcting for Publication Bias Using Only Significant Results. Perspect. Psychol. Sci. 9, 666-681. https://doi.org/10.1177/1745691614553988

Soames, R.W., Atha, J., 1981. The role of the antigravity musculature during quiet standing in man. Eur. J. Appl. Physiol. Occup. Physiol. 47, 159-167. https://doi.org/10.1007/BF00421668

Suetta, C., Haddock, B., Alcazar, J., Noerst, T., Hansen, O.M., Ludvig, H., Kamper, R.S., Schnohr, P., Prescott, E., Andersen, L.L., Frandsen, U., Aagaard, P., Bülow, J., Hovind, P., Simonsen, L., 2019. The Copenhagen Sarcopenia Study: lean mass, strength, power, and physical function in a Danish cohort aged 20-93 years. J. Cachexia. Sarcopenia Muscle 1-13. https://doi.org/10.1002/jcsm.12477 
Taylor, J.T., Petersen, N., Butler, J.E., Gandevia, S.C., 2000. Ischaemia after exercise does not reduce responses of human motoneurones to cortical or corticospinal tract stimulation. J. Physiol. 525, 793-801. https://doi.org/10.1111/j.1469-7793.2000.00793.x

Tomás, M.T., Galán-Mercant, A., Carnero, E.A., Fernandes, B., 2018. Functional capacity and levels of physical activity in aging: A 3-year follow-up. Front. Med. 4, 1-8. https://doi.org/10.3389/fmed.2017.00244

Unhjem, R.J., Nygård, M., Hoven, L.T. van den, Sidhu, S.K., Hoff, J., Wang, E., 2016. Lifelong strength training mitigates the age-related decline in efferent drive. J. Appl. Physiol. 121, 415-423. https://doi.org/10.1152/japplphysiol.00117.2016

Vaillancourt, D.E., Larsson, L., Newell, K.M., 2003. Effects of aging on force variability, single motor unit discharge patterns, and the structure of 10, 20, and $40 \mathrm{~Hz}$ EMG activity. Neurobiol. Aging 24, 25-35. https://doi.org/10.1016/S0197-4580(02)00014-3

Vandervoort, A. a., 2002. Aging of the human neuromuscular system. Muscle and Nerve 25, 17-25. https://doi.org/10.1002/mus. 1215

Viechtbauer, W., 2010. Conducting meta-analyses in R with the metafor. J. Stat. Softw. 36, 1-48. https://doi.org/10.18637/jss.v036.i03

Vijayashankar, N., Brody, H., 1979. A quantitative study of the pigmented neurons in the nuclei locus coeruleus and subcoeruleus in man as related to aging. J. Neuropathol. Exp. Neurol. 38, 490-497. https://doi.org/10.1097/00005072-197909000-00004

Wilson, J.M., Thompson, C.K., Miller, L.C., Heckman, C.J., 2015. Intrinsic excitability of human motoneurons in biceps brachii versus triceps brachii. J. Neurophysiol. 113, 3692-3699. https://doi.org/10.1152/jn.00960.2014 
Table 1. Studies characteristics

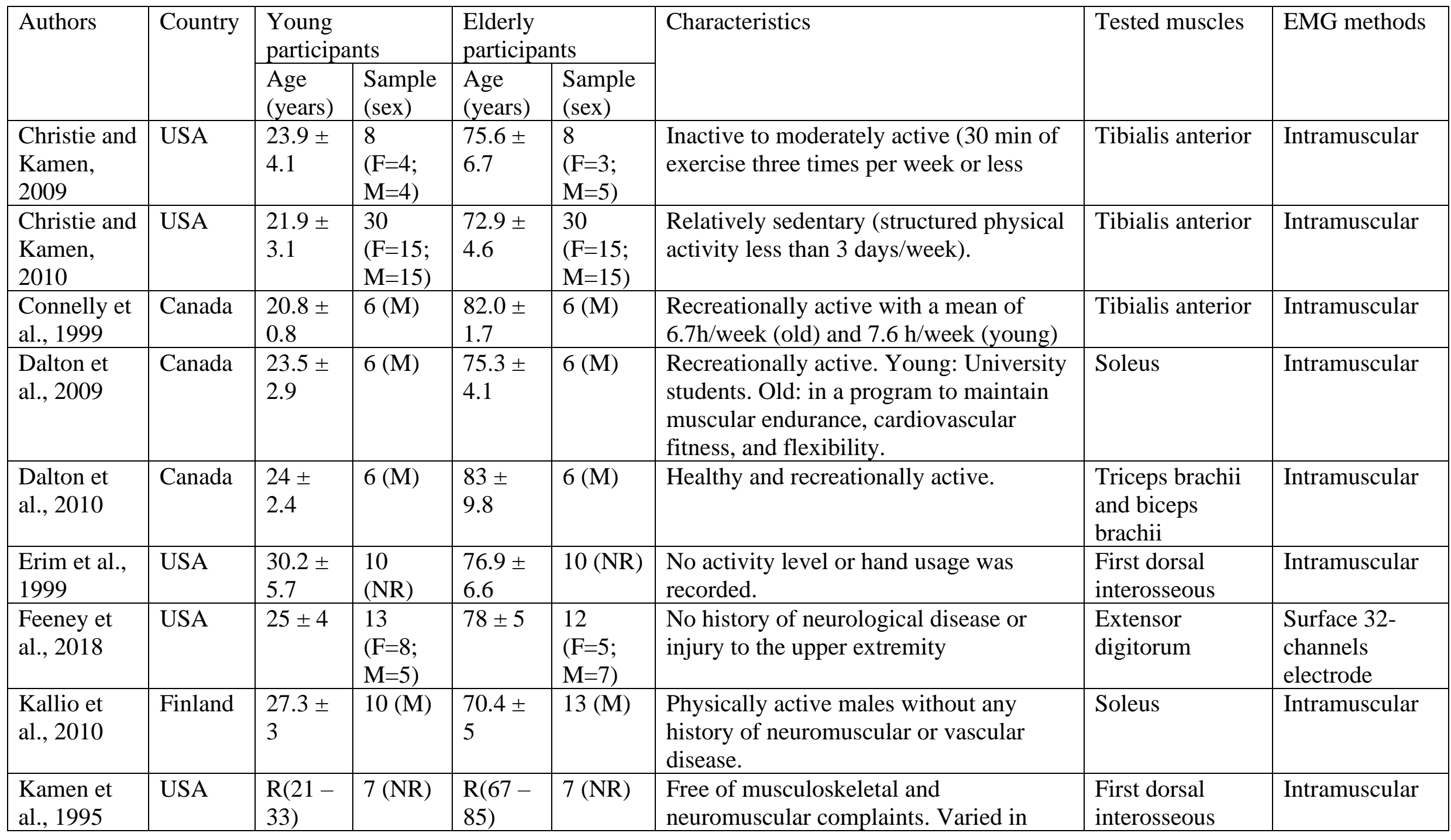




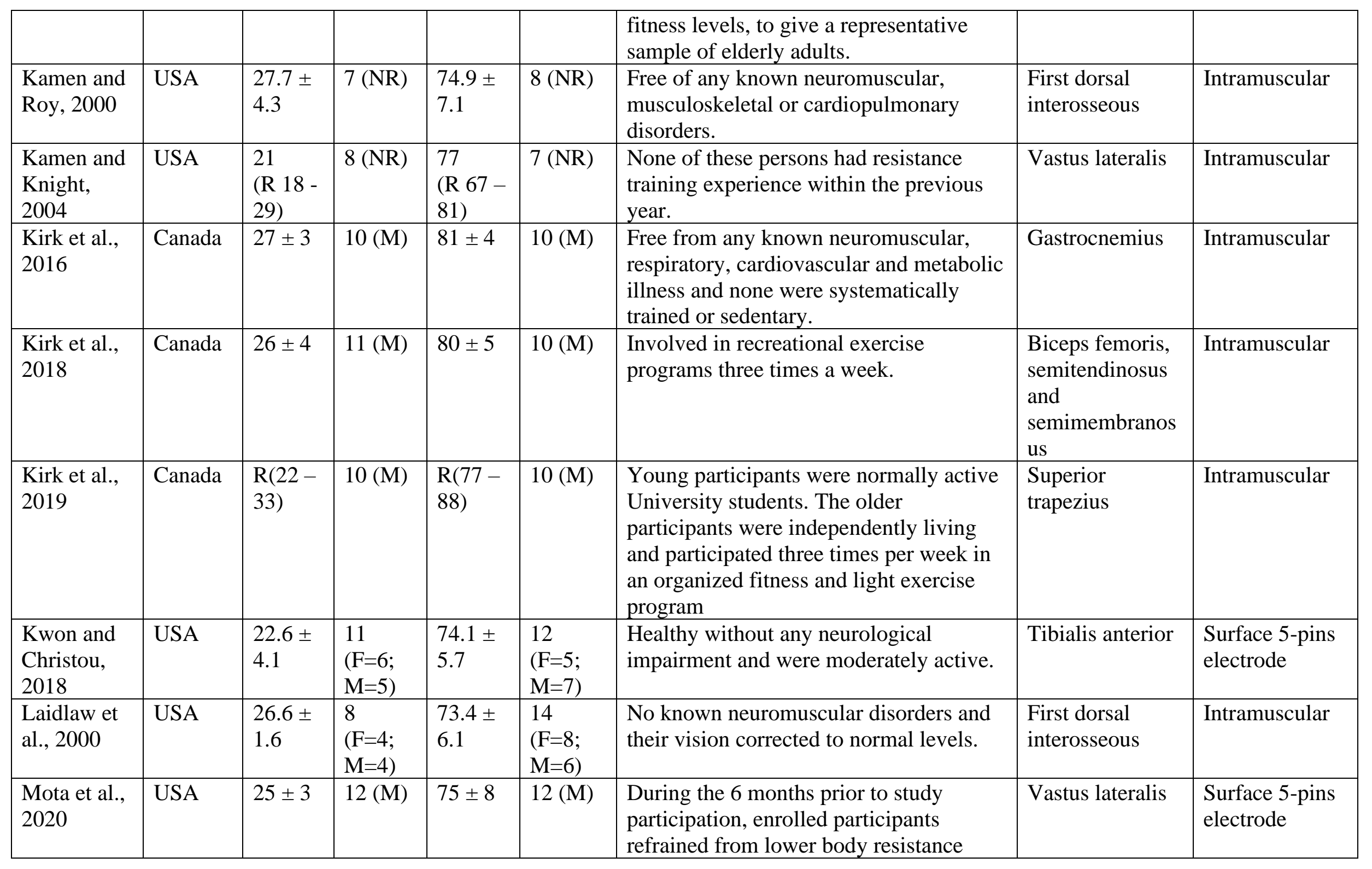




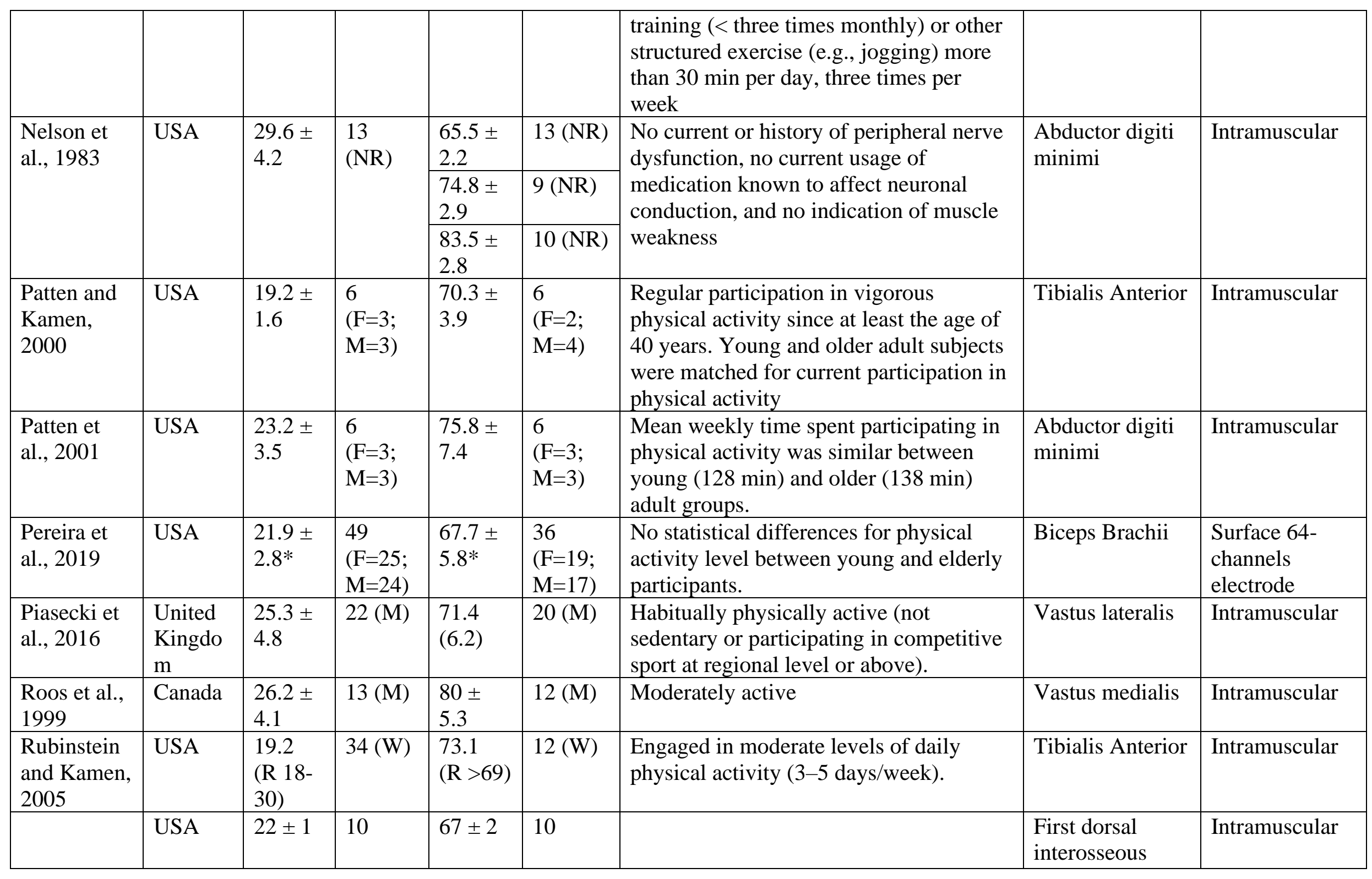




\begin{tabular}{|l|l|l|l|l|l|l|}
\hline $\begin{array}{l}\text { Vaillancour } \\
\text { t et al., } \\
2003\end{array}$ & & $\begin{array}{l}(\mathrm{F}=5 ; \\
\mathrm{M}=5)\end{array}$ & & $\begin{array}{l}(\mathrm{F}=5 ; \\
\mathrm{M}=5)\end{array}$ & $\begin{array}{l}\text { The subjects were naive to the purpose of } \\
\text { the experiment and none had a history of } \\
\text { a neurological disorder }\end{array}$ & $\begin{array}{l}10 \\
(\mathrm{~F}=5 ; \\
\mathrm{M}=5)\end{array}$
\end{tabular}

$\mathrm{R}$ = range; EMG, electromyography; NR, not reported; $\mathrm{M}$, male; F, female; *pooled mean \pm standard deviation from male and female groups. 